\title{
Menhaden Fish Oil, n-3 Polyunsaturated Fatty Acids, and Protection of Newborn Rats from Oxygen Toxicity
}

\author{
ILENE R. S. SOSENKO, SHEILA M. INNIS, AND LEE FRANK
}

From the Divisions of Neonatology and Pulmonary Research, Calvin and Flavia Oak Asthma Research and Treatment Facility, Departments of Pediatrics and Medicine, University of Miami School of Medicine, Miami, Florida 33101 [I.R.SS., L.F.J, and Department of Pediatrics, University of British Columbia, Vancouver, Canada [S.M.I.]

\begin{abstract}
We have previously reported that newborn rats born to mothers fed a high $\mathrm{n}-6$ polyunsaturated fatty acid (PUFA) (safflower oil) diet demonstrated increased n-6 PUFA in lung lipids and superior tolerance to high oxygen exposure. In the present study, we explored whether high n-3 PUFA might also protect against hyperoxic damage and by what mechanism. Adult female rats were fed either regular rat chow, a high n-3 (menhaden fish oil-based) diet, or a high n-6 (safflower oil-based) diet for $6 \mathrm{wk}$ before and then throughout pregnancy and lactation. Newborn offspring of the high n-3 (fish oil) dams demonstrated increased n-3 PUFA (i.e. eicosapentaenoic and docosahexaenoic acid) and decreased n-6 PUFA (i.e. linoleic and arachidonic acid) in their lung lipids compared to the other two diet groups. The high n-6 (safflower oil) offspring had the opposite PUFA lung lipid pattern (with increases in total n-6 fatty acids and decreases in total n-3 fatty acids). The high n-3 offspring demonstrated markedly decreased lung levels of prostaglandin $\mathbf{E}_{2}, \mathrm{~F}_{2 \alpha}$ and thromboxane $B_{2}$, whereas the high n-6 offspring had higher eicosanoid levels than the regular diet offspring. Offspring of both high n-6 and high n-3 diet dams demonstrated essentially the same superior hyperoxic tolerance compared to regular diet offspring $17-\mathrm{d}\left(>95 \% \mathrm{O}_{2}\right)$ survival rates of 110/115 and 99/109, respectively, versus $70 / 91, p$ $<0.01$. These studies lend further support to the speculation that increasing lung PUFA content may provide the newborn lung with increased ability to scavenge oxygenfree radicals and thus may serve to protect against oxygen toxicity. (Pediatr Res 25:399-404, 1989)
\end{abstract}

\section{Abbreviations}

PUFA, polyunsaturated fatty acids

EPA, eicosapentaenoic acid

DHA, docosahexaenoic acid

DSPC, disaturated phosphatidylcholine

SOD, superoxide dismutase

CAT, catalase

GP, glutathione peroxidase

Received July 21, 1988; accepted November 22, 1988

Reprint requests and correspondence Ilene R. S. Sosenko, M.D., University of Miami School of Medicine, Pulmonary Research (R-120), P.O. Box 016960 Miami. FL 33101

Supported by The March of Dimes Basil O'Connor Grant 5-540, an American Lung Association Grant (I.R.S.S.); Medical Research Council of Canada Scholarship and Research Investigatorship for the British Columbia Children's Hospital (S.M.I.): and NIH Research Grant HL26029 and NHLBI Research Carcer Development Award HLO1230 (L.F.).
Common nursery practices consist of a several-day interval between the birth of a very low birth wt oxygen-requiring premature infant and the initial administration of lipid nutrition. Because of the immaturity of the pulmonary antioxidant defense systems in the premature (1) and the possible role lipids might play in protecting the lung from the toxic effects of high $\mathrm{O}_{2}$, this withholding of lipids from these critically ill neonates might increase their risk of developing the chronic lung disease, bronchopulmonary dysplasia.

In a previous study exploring the protective role of specific lipids on pulmonary $\mathrm{O}_{2}$ toxicity, we demonstrated that pregnant rats fed a high PUFA diet (safflower oil) produced offspring with increased PUFA in their lung lipids and superior survival in hyperoxia (2). One possible explanation for the protective effect of high PUFA has been proposed by Dormandy (3), who hypothesized that PUFA, located in noncritical, nonmembrane sites, and immediately replaced after their own autooxidation, could serve as avid scavengers of excess $\mathrm{O}_{2}$-free radicals, function as an antioxidant, and thereby protect cells from $\mathrm{O}_{2}$ toxicity.

Whereas safflower oil contains PUFA primarily of the $n-6$ family of fatty acids (i.e linoleic acid, 18:2 n-6), menhaden or fish oil, linked epidemiologically with decreased thrombosisrelated cardiovascular disease $(4,5)$, contains PUFA primarily of the n-3 family, with long carbon chains and multiple double bonds (i.e. EPA, 20:5 n-3; and DHA, 22:6 n-3).

The long-chain $n-3$ family fatty acids differ from the $n-6$ family fatty acids in their prefe rence to serve as substrate for the lipoxygenase and cyclooxygenase enzymes and in the biologic properties of their oxygenated cyclooxygenase and lipoxygenase products (5-8). In addition, n-3 family fatty acids are major PUFA components in the membranes of the central nervous system and retina, with accumulation into these membranes occurring almost exclusively during the last trimester of the human gestation $(9-11)$.

With these facts as background, we undertook the present study to determine whether menhaden oil, providing elevated PUFA of the n-3, rather than the $n-6$ family, would be associated with superior tolerance to high $\mathrm{O}_{2}$ exposure in the neonatal rat. In addition, if superior hyperoxic tolerance did result from menhaden oil nutrition, might this protection be related to altered lung lipid PUFA composition, to fish oil's effect on lung eicosanoids, and/or to altered antioxidant enzyme development or induction during hyperoxia.

\section{MATERIALS AND METHODS}

Animals, diets: Adult Sprague-Dawley albino female rats $(\sim 200 \mathrm{~g})$ were fed one of three diets ad libitum: 1 ) standard rat Chow (\#5001, Ralston-Purina, Co., St. Louis, MO); (5\% fat as a mixture of animal and vegetable fats; double bond index $=74$ ); 
2) high n-3 family PUFA diet ("fat-free" test diet \#15750, United States Biochemical Corp., Cleveland, OH, plus 10\% [by wt] menhaden oil; double bond index $=173$ ); 3) high $n-6$ family PUFA diet ("fat-free" test diet plus $10 \%$ [by wt] safflower oil; double bond index $=162$ ). Diets 1,2 , and 3 were essentially comparable in protein content $(23 \%, 18 \%, 18 \%$, respectively), carbohydrate content $(66 \%, 52 \%, 52 \%)$, and caloric density $(4.0$, $3.7,3.7 \mathrm{cal} / \mathrm{g}$ ). The comparative composition of the three test diets is seen in Table 1. Rats were fed the respective diets for at least $3 \mathrm{wk}$ before breeding and then throughout pregnancy and lactation. Breeding was accomplished by placing male and female animals together overnight, checking for sperm-positive vaginal smears the next morning, and considering the midpoint of the cohabitation period as the onset of pregnancy.

Several litters from the high n-3 PUFA (menhaden oil) diet group and regular diet group were killed prematurely at d 20 or 21 of gestation, after term delivery at $22 \mathrm{~d}$ of gestation, or at 1 or $7 \mathrm{~d}$ of postnatal age. Premature pups were delivered by hysterotomy with the dam under pentobarbital anesthesia; newborn rats were obtained after normal parturition, either within 6 $h$ of the beginning of delivery of the first pup or after $24 \mathrm{~h}$ of life. Fetal, newborn, 1-d- or 7-d-old rat lungs were perfused immediately in situ via the pulmonary artery using cold saline. The perfused fetal and newborn lungs were removed, stripped of nonpulmonary tissue, and homogenized in 20 to 30 times their wt of cold saline in a Brinkmann polytron (high speed, $90 \mathrm{~s}$ ), (Brinkmann Instruments, Inc., Westbury, NY). For preterm or small newborn rats, two to four lungs were pooled and homogenized to obtain adequate tissue for the assays.

Antioxidant enzyme, phospholipid and fatty acid analyses. Aliquots of the lung homogenate were analyzed for antioxidant enzyme activities using standard spectrophotometric assays for SOD (12), CAT (13), and GP (14), and for DNA and protein content $(15,16)$. Purified enzyme standards (SOD, CAT) and DNA standard were obtained from Sigma Diagnostics (St. Louis, MO) and GP from Boehringer-Mannheim, Houston, TX). Results of antioxidant enzyme analyses were expressed as $U$ of enzyme activity/mg of DNA. For DSPC analysis, a separate aliquot of lung homogenate was subjected to lipid extraction (17), reaction with osmium tetroxide (18), and assay for inorganic phosphorus using the method of Morrison (19). A known quantity of ${ }^{14} \mathrm{C}$-dipalmitoyl-phosphatidylcholine (New England $\mathrm{Nu}$ clear, North Billerica, MA) was added before lipid extraction,

Table 1. Purtial fatty acid content of three experimental diets

\begin{tabular}{|c|c|c|c|}
\hline Fatty acid (\%) & Regular & Safflower & Menhaden \\
\hline $\begin{array}{l}16: 0 \\
\text { (palmitic) }\end{array}$ & 20 & 6 & 17 \\
\hline $\begin{array}{l}18: 2 n-6 \\
\text { (linoleic) }\end{array}$ & 27 & 81 & 2 \\
\hline $\begin{array}{l}18: 3 n-3 \\
\text { (linoleic) }\end{array}$ & 3 & 1 & 2 \\
\hline $\begin{array}{l}20: 4 n-6 \\
\text { (arachidonic) }\end{array}$ & - & - & 2 \\
\hline $\begin{array}{l}20: 5 n-3 \\
\text { (EPA) }\end{array}$ & 1 & - & 17 \\
\hline $\begin{array}{l}22: 6 n-3 \\
(\mathrm{DHA})\end{array}$ & 1 & - & 8 \\
\hline$n-6 / n-3 *$ & 5 & 101 & 0.1 \\
\hline Double bond index $\dagger$ & 74 & 162 & 173 \\
\hline Supplier & Ralston-Purina & Beatrice Foods & $\mathrm{ICN}$ \\
\hline
\end{tabular}

*n-6, n-3: each represents a family of structurally related fatty acids based on the position of the first double bond from the methyl end. $n$ $6 / n-3$ is the ratio of the total $n-6 / n-3$ family of fatty acids in diet.

$\dagger$ Double bond index $=$ the sum of [the number of unsaturated double bonds in each specific fatty acid multiplied by the percentage of each specific fatty acid]. and aliquots were counted at each step to estimate and correct for sequential losses. DSPC was expressed as $\mathrm{mg} / \mathrm{g}$ wet lung wt.

Lungs from 1-d-old rat offspring from regular diet, high n-3 PUFA (menhaden) diet, and high n-6 PUFA (safflower) diet were perfused with iced saline as described and frozen in liquid nitrogen for fatty acid analysis. The frozen tissue was homogenized and aliquoted for protein, and total lipids were extracted using the procedure of Folch et al. (20). Total fatty acids were converted to their respective methyl esters with methanolic $\mathrm{HCl}$ and separated and quantitated by capillary column gas-liquid chromatography (21). C17:0 was used as the internal standard. The fatty composition of lung phospholipids (from 7-d-old regular diet and high n-3 diet offspring) was determined after separation of phospholipids from other lipid classes by plate chromatography (22). Protein was assayed according to the method of Lowry et al. (23).

Nursing female rats maintained on either regular rat Chow or high n-3 PUFA diet (menhaden oil) were selected at random for milk collection. Rat milk was collected by manual expression from lightly anesthetized dams, frozen at $-80^{\circ} \mathrm{C}$, and assayed for total lipid fatty acid composition. The frozen samples were thawed in cold water, then rapidly heated to $80^{\circ} \mathrm{C}$ and held for 1 min to prevent lipase activity as described by Bitman et al. (24). Total lipids were extracted using the procedure of Folch et al. (20), and the fatty acids were converted to their respective methyl esters with methanolic $\mathrm{HCl}$ after addition of $\mathrm{C} 13: 0$ and C17:0 as internal standards. The fatty acid methyl esters were separated and quantitated by capillary column gas-liquid chromatography. The gas-liquid chromatography equipment and operating conditions were used as described in detail (22), except that the column oven was programmed from 80 to $160^{\circ} \mathrm{C}$ at $20^{\circ} /$ $\min$, then to $200^{\circ} \mathrm{C}$ at $5^{\circ} / \mathrm{min}$.

Exposure to hyperoxia. Multiple litters (9-11 pups) of newborn rats from each of the three diet groups were placed with their mothers into $>95 \% \mathrm{O}_{2}$ (or room air) at $6-12 \mathrm{~h}$ of life. Details of the continually monitored exposure conditions have been reported earlier (25). Dams from the same diet group were rotated between room air and $>95 \% \mathrm{O}_{2}$ litters every $24 \mathrm{~h}$ to prevent $\mathrm{O}_{2-}$ induced illness with consequent poor mothering. Weight gain and survival of newborn rats from each group was recorded daily for $7 \mathrm{~d}$. In addition, after $7 \mathrm{~d}$ of exposure, random surviving offspring from each diet group were removed from high $\mathrm{O}_{2}$ or from companion room air-exposed litters, killed and their lungs processed and assayed for DSPC and antioxidant enzymes as described above. We also evaluated in a separate experiment the clinicopathologic condition of pups surviving a 7-d hyperoxic exposure. We devised a scoring system that semi-quantitatively scored the pups in blinded fashion from 0 (normal) to 2 (markedly abnormal) on five parameters of $\mathrm{O}_{2}$ toxicity: degree of respiratory distress, pleural fluid accumulation, and gross appearance of edema, atelectasis, and lung hemorrhage.

Prostaglandin assays. After $5 \mathrm{~d}$ of either $>95 \% \mathrm{O}_{2}$ or room air exposure, offspring from the three diet groups were killed, and their lungs were removed and homogenized as described above. The homogenizing buffer for these studies, however, contained acetylsalicylic acid $(15 \mathrm{mM})$. Fresh homogenates were assayed for prostaglandin $\mathrm{E}_{2}$, prostaglandin $\mathrm{F}_{2 \alpha}$, and thromboxane $\mathrm{B}_{2}$, using specific RIA test kits (Seragen, Inc., Cambridge, MA).

Statistics. Statistics were performed using Chi-square analysis for survival data, analysis of variance for fatty acid data and Student's $t$ test for antioxidant enzyme and phospholipid data (26).

\section{RESULTS}

Growth and biochemical development of offspring. Both the high n-3 PUFA diet and the high n-6 PUFA diet were well accepted by the female rats. Birth wt and fetal and neonatal growth were not different in offspring of the two experimental 
diet groups and did not differ from offspring of rats fed regular rat Chow.

The comparative development of the antioxidant enzyme system and the surfactant system in the high n-3 PUFA (menhaden) diet offspring and regular diet offspring can be seen in Table 2. Offspring of the high n-3 PUFA diet did not demonstrate advanced development of the three antioxidant enzymes-SOD, $\mathrm{CAT}$, and GP-or of surfactant compared to the regular diet offspring. In fact, significantly depressed lung GP enzyme activity was found in the term and premature menhaden diet offspring. This finding suggests that a deficient level of selenium may exist in the menhaden oil diet. (Arrangements are underway to have selenium levels in the diets evaluated by other investigators experienced with the analysis procedure).

The partial fatty acid profile of the rat milk from the dams of the three diet groups is seen in Table 3. Whereas the rat milk of the high n-6 (safflower) diet dams had increased linoleic acid (31\%) compared to regular diet (16.8\%) and menhaden diet milk (1.5\%), and very low $n-3$ family PUFA, the milk of menhaden dams demonstrated, in addition to dramatic decreases in linoleic acid, significant increases in n-3 family PUFA.

When the fatty acid composition of total lung lipid was deter-

Table 2. Comparative antioxidant enzyme and surfactant development in offspring of menhaden oil and regular diet rats*

\begin{tabular}{ccccc}
\hline & \multicolumn{3}{c}{$\mathrm{U} / \mathrm{mg}$ of DNA } & $\mathrm{mg} / \mathrm{g}$ lung \\
\cline { 2 - 4 } Gestation (d) & SOD & CAT & GP & DSPC \\
\hline 20 & & & & \\
$\quad$ Regular (8) & 24.4 & 240 & 0.514 & 2.06 \\
$\quad$ Menhaden (6) & 23.4 & 228 & $0.388 \dagger$ & 2.14 \\
$21 \quad$ & & & & \\
$\quad$ Regular (8) & 18.6 & 347 & 0.676 & 2.87 \\
$\quad$ Menhaden (8) & 18.3 & 326 & 0.416 & 3.13 \\
22 & & & & \\
$\quad$ Regular (6) & 25.9 & 541 & 1.041 & 5.20 \\
$\quad$ Menhaden (6) & 22.7 & 492 & $0.488 \dagger$ & 5.50 \\
\hline
\end{tabular}

* Mean values for $n$ of pooled lung samples in parentheses.

$\dagger p<0.05$ difference between diet groups.

Table 3. Partial fatty acid pattern of rat milk from high n-3 PUFA diet (menhaden oil), high n-6 PUFA diet (safflower oil),

\begin{tabular}{cccccc}
\multicolumn{5}{c}{ and regular diet rats* } \\
\hline \multirow{5}{*}{$\begin{array}{c}\text { Diet } \\
\text { Group }\end{array}$} & $18: 2 \mathrm{n}-6$ & $20: 4 \mathrm{n}-6$ & $20: 5 \mathrm{n}-3$ & $22: 6 \mathrm{n}-3$ & $\mathrm{n}-6 / \mathrm{n}-3$ \\
\hline $\begin{array}{l}\text { Regular } \\
\text { Men- }\end{array}$ & 16.8 & 1.6 & 0.4 & 0.8 & 9.6 \\
haden & $1.5 \dagger$ & 1.3 & $9.0 \dagger$ & $6.8 \dagger$ & $0.21 \dagger$ \\
Safflower & $31.0 \ddagger$ & 1.3 & $0.02 \ddagger$ & $0.0 \ddagger$ & $471 \ddagger$ \\
$*$ Mean values; all $\mathrm{SD} \leq 1.0 ; n=3-4$ samples/diet group. \\
$+p \leq 0.05$ vs. regular and safflower. \\
$\ddagger p \leq 0.05$ vs. regular and menhaden.
\end{tabular}

mined in 1-d-old offspring of the three diet groups (Table 4), the high n-3 PUFA offspring lung lipid was found to have significantly less linoleic acid (18:2 n-6) and arachidonic acid (20:4 n6) but significantly increased amounts of EPA (20:5n-3) and DHA $(22: 6 n-3)$ and a markedly reduced $n-6 / n-3$ ratio $(0.19)$ compared to regular diet (2.4) and high n-6 PUFA (safflower) diet (37.0) offspring. Conversely, the high n-6 PUFA offspring had increases in linoleic acid and total n- 6 family PUFA and significant decreases in total n-3 family PUFA compared to the menhaden and regular diet offspring.

The separation of total lung lipid into phospholipid and triacylglycerol subclasses with subsequent fatty acid analyses (Table 5) revealed similar changes in the 7-d-old high n-3 PUFA (menhaden) versus regular diet offspring in each lipid subclass compared to what was seen in the total lung lipid aggregate. However, even more marked differences in the double bond index $(282$ versus 182 , menhaden versus regular) was found in the triacylglycerol subclass of the lung lipid compared to what was found in the phospholipid subclass (double bond index: 185 versus 155 , menhaden versus regular).

Exposure to hyperoxia. Both the high n-3 PUFA offspring and the high n-6 offspring demonstrated similar superior survival after 7 d of hyperoxia (99 out of 109, for menhaden offspring; 110 out of 115 for safflower offspring) compared to regular diet offspring (70 out of 91), Figure 1. These results represent newborn rat pups from the three diet groups placed in high $\mathrm{O}_{2}$ within $12 \mathrm{~h}$ of birth; neonatal pups placed in hyperoxia after several days of life would be expected to have a somewhat higher 7-d hyperoxic survival rate.

In addition to their improved survival rate in hyperoxia, the 7-d survivors from the menhaden oil diet group demonstrated superior clinical/pathologic status by semi-quantitative (blinded) scoring compared to the regular diet group survivors. The total clinicopathologic score (based on assessing five parameters, each giving a maximal lung injury score of 2.0 and a minimal score of 0$)$ was $1.20 \pm 0.54(n=10)$ for the fish oil survivors versus

Table 5. Partial fatty acid components of lung phospholipids and triacylglycerols in 7-d-old offspring of high n-3 PUFA (menhaden oil) and regular diet rats*

\begin{tabular}{|c|c|c|c|c|}
\hline \multirow[b]{2}{*}{$\mathrm{FA}(\%)$} & \multicolumn{2}{|c|}{ Phospholipids $\dagger$} & \multicolumn{2}{|c|}{ Triacylglycerols } \\
\hline & Menhaden & Regular & Menhaden & Regular \\
\hline $18: 2 n-6$ & $1.5+$ & 7.0 & $1.7+$ & 14.8 \\
\hline $20: 4 n-6$ & $4.5+$ & 16.0 & $1.6+$ & 4.7 \\
\hline $22: 5 n-3$ & $5.5+$ & 2.6 & $14.0 \%$ & 5.1 \\
\hline $22: 6 n-3$ & $8.8 \hbar$ & 4.7 & $25.0+$ & 9.0 \\
\hline $\begin{array}{l}\text { Double bond in- } \\
\text { dex }\end{array}$ & $185 \ddagger$ & 155 & $282+$ & 182 \\
\hline
\end{tabular}

* Mean values; $n=3$ samples/diet group.

$\dagger$ Phospholipids represent predominately membrane-associated cell lipid, whereas triacylglycerols are predominantly nonmembrane, intracellular lipid.

$¥$ Significantly different between diet groups at $p<0.05$.

Table 4. Partial fatty acid composition of lung lipids*

\begin{tabular}{|c|c|c|c|c|c|c|c|}
\hline \multirow[b]{2}{*}{ Diet group } & \multicolumn{4}{|c|}{ Fatty acid (\%) } & \multirow[b]{2}{*}{ Total $n-6$} & \multirow[b]{2}{*}{ Total $n-3$} & \multirow[b]{2}{*}{$n-6 / n-3$} \\
\hline & $18: 2 n-6$ & $20: 4 n-6$ & $20: 5 n-3$ & $22: 6 n-3$ & & & \\
\hline Regular & 5 & 12 & 1 & 6 & 22 & 9 & 2.4 \\
\hline $\begin{array}{l}\text { Men- } \\
\text { haden }\end{array}$ & $0.6 \dagger$ & $3 \dagger$ & $9 \dagger$ & $11 \uparrow$ & $5 \dagger$ & $26 \dagger$ & $0.19 \dagger$ \\
\hline Safflower & $11 \ddagger$ & 14 & 0.1 & $0.5 \neq$ & $37 \ddagger$ & $1+$ & $37 \ddagger$ \\
\hline
\end{tabular}

* Mean values; all $\mathrm{SD}<1.0 ; n=2-7$ samples/diet group.

$+p \leq 0.05$ menhaden $v s$. regular.

$+p \leq 0.05$ safflower $v s$. regular. 


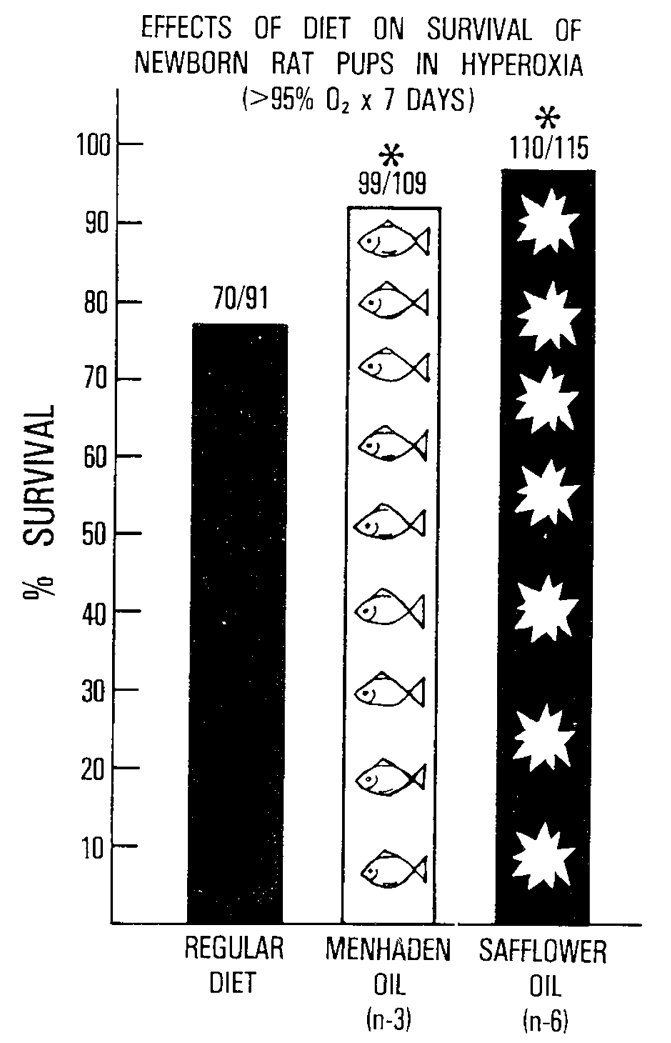

Fig. 1. Percentage survival of offspring of three diet groups after $7 \mathrm{~d}$ of hyperoxic exposure $\left(>95 \% \mathrm{O}_{2}\right) .\left({ }^{*} p<0.0 \mathrm{l}\right.$ versus regular diet group).

$2.35 \pm 1.53(n=10)$ for the regular diet $\mathrm{O}_{2}$ survivors $(p<0.05$ between groups).

After $7 \mathrm{~d}$ of hyperoxia, both groups of diet pups manifested significantly increased antioxidant enzyme responses to hyperoxia. No statistically significant differences were present in the magnitude of increase of the three antioxidant enzymes and in DSPC in the high n-3 PUFA diet (SOD: $\uparrow 19 \%$, CAT: $\uparrow 82 \%$, GP: $\uparrow 140 \%$, DSPC: $0 \%$ ) compared to the regular diet offspring (SOD: $\uparrow 36 \%$, CAT: $\uparrow 55 \%$, GP: $\uparrow 95 \%$, DSPC: $\downarrow 10 \%)$. Results of increases in AOE and DSPC after $7 \mathrm{~d}$ of $>95 \% \mathrm{O}_{2}$ in high $\mathrm{n}-6$ (safflower) compared to regular diet offspring have been reported previously and were likewise found not to be different in magnitude compared to the regular diet group (2).

Prostaglandins, thromboxane measurements. Lung tissue prostaglandin $\mathrm{E}_{2}$ and $\mathrm{F}_{2 \ll x}$ and thromboxane $\mathrm{B}_{2}$ levels from 4- to 5-dold offspring from the three diet groups are depicted in Figure $2 A$. High n-3 (menhaden) offspring had comparatively much lower levels of all three eicosanoids than the other diet groups, whereas the high $n-6$ (safflower) offspring tended to show higher lung eicosanoid levels. When eicosanoid values from the airexposed animals from the three dietary groups were compared with the values obtained after $5 \mathrm{~d}$ of $>95 \% \mathrm{O}_{2}$ exposure, the lungs of $\mathrm{O}_{2}$-exposed pups from the three groups had 2- to 3-fold elevations in all eicosanoids measured, except for a lack of any significant rise in prostaglandin $E_{2}$ in the menhaden diet group. After hyperoxic exposure, high n-3 offspring demonstrated obviously lower prostaglandins and thromboxane $\mathrm{B}_{2}$ levels compared to the regular and high n-6 diet $\mathrm{O}_{2}$-exposed offspring, whereas high n-6 offspring had significantly increased thromboxane $\mathrm{B}_{2}$ compared to regular and high $\mathrm{n}-3$ pups (Fig. $2 B$ ).

\section{DISCUSSION}

Fish or marine oil, of which menhaden oil is an example, has received a flurry of recent attention in both the lay and professional press. Epidemiologic investigations have suggested a pos- sible link between a diet high in fish oil and the reduced incidence of thrombosis-related ischemic heart disease found in Greenland Eskimos $(4,5)$. A number of studies in humans and in a variety of experimental animals have demonstrated that a fish oil diet (containing high levels of $n-3$ family PUFA) can result in rapid increases in the n-3 PUFA composition of the lung, kidney, spleen, liver, heart, plasma, red blood cells, and macrophages (27-33). Similar modification of the n-3 PUFA composition of cells in culture can be accomplished by changing the n-3 fatty acid content of the culture medium (33). Conversely, deprivation of $\mathrm{n}-3$ family fatty acids to developing animals results in decreases in n-3 PUFA accumulation in brain and retinal membranes (34, $35)$.

The significance of these $\mathrm{n}-3$ fatty acid changes in tissue lipids relates to changes in cell properties and/or cell functions, such as changes in the activity of membrane-associated cellular enzymes (i.e. the activity of membrane-bound adenylate cyclase in rat liver is modulated by the nature of its membrane lipid environment) and membrane fluidity (i.e. altering the lipid composition of hepatocytes produces changes in plasma membrane fluidity and increased activity of $\left[\mathrm{Na}^{+}-\mathrm{K}^{+}\right.$-dependent] ADP [36, 37]). Specifically relating to n-3 fatty acids, lung microsomes containing increased phospholipid n-3 fatty acids (as a result of menhaden oil diet) demonstrate decreased ability to convert arachidonic acid into thromboxane (27). And importantly, ex-

\section{LUNG TISSUE PG AND TX MEASUREMENTS}

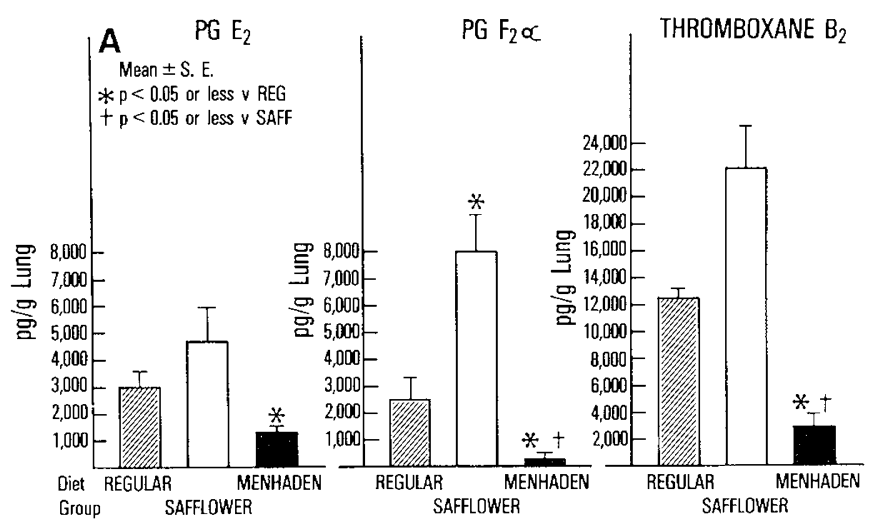

LUNG TISSUE PG + TX FROM NEWBORN RATS AFTER 5 DAYS $>95 \% \mathrm{O}_{2}$ Exposure

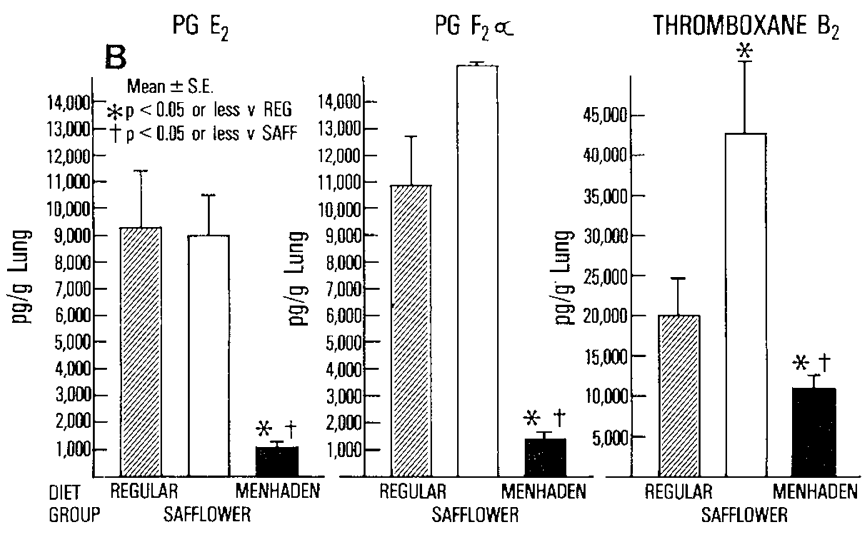

Fig. 2. A, lung tissue prostaglandin $\mathrm{E}_{2}, \mathrm{~F}_{2 \alpha}$, and thromboxane $\mathrm{B}_{2}$ levels in 5-d-old offspring from the three diet groups; $n=3-4$ samples/ group/prostaglandin assay ( $\dagger p<0.05$ versus high $\mathrm{n}-6$ (safflower) offspring; ${ }^{*} p<0.05$ versus regular diet offspring). $B$, lung tissue prostaglandin $E_{2}, F_{2 k}$, and thromboxane $B_{2}$ levels in 5-d-old offspring from the three diet groups after $5 \mathrm{~d}$ of $>95 \% \mathrm{O}_{2}$ exposure; $n=3-4$ samples/ group/assay ( $+p<0.05$ or less versus high n-6 (safflower) offspring; ${ }^{*} p<$ 0.05 or less versus regular diet offspring). 
perimental animals with deficient accumulation of the $n-3$ fatty acid DHA (22:6 n-3) in brain and retinal membranes are found to have decreased discrimination learning and visual acuity (34, 35 ).

Our interest in n-3 PUFA and in menhaden oil stems from our previous observation that offspring of rats fed a high PUFA diet (safflower oil) consistently demonstrated superior tolerance to high $\mathrm{O}_{2}$ exposure, and this increased resistance to hyperoxia was associated with increased lung PUFA levels (2). We chose menhaden oil to further these investigations for several reasons First, menhaden oil represents a relatively PUFA-rich dietary oil, with a high double bond index similar to safflower oil. Secondly, the PUFA composition of menhaden oil is, however, markedly different from the PUFA content of safflower oil. Menhaden oil contains increased n-3 family fatty acids (and decreased n-6 family PUFA). Finally, as the hyperoxic protective effect of safflower oil could have been related to an increased capacity for eicosanoid production, a fish oil diet could provide high lung PUFA content yet depress eicosanoid production during hyperoxic exposure $(27,32)$.

As anticipated from our previous studies (2) and those of other investigators (28), offspring of rats fed modified PUFA diets had modifications in the fatty acid composition of their lung lipid. Specifically, we found that offspring of rats fed a high n-3 PUFA diet in the form of menhaden oil had increased n-3 PUFA in total lung lipids. In addition, in the menhaden-diet offspring, although the increases in n-3 PUFA were observed in both the phospholipid and triacylglycerol fractions of lung lipid, more marked enrichment with high unsaturated $n-3$ fatty acids was apparent in the triacylglycerol fraction than in the phospholipid fraction (Table 5).

In association with the marked increases in n-3 PUFA in their lung lipid, offspring of menhaden oil diet rats demonstrated increased tolerance to high $\mathrm{O}_{2}$ exposure compared to regular diet offspring. In fact, the survival rate after $7 \mathrm{~d}$ of $>95 \% \mathrm{O}_{2}$ found in the menhaden oil offspring was remarkably similar to the hyperoxic survival found in safflower oil offspring both in this and in our previous study (2). The mechanism whereby increases in maternal dietary PUFA (with consequent increases in rat milk PUFA and ultimately in lung tissue PUFA of the offspring) result in protection against the toxic events of high $\mathrm{O}_{2}$ remains speculative. The high PUFA offspring did not have significantly augmented antioxidant enzyme system or surfactant development nor a greater ability to induce a protective antioxidant enzyme response during hyperoxia. Calculations of dietary intake of vitamins $\mathrm{E}$ and $\mathrm{A}$ in the three diets studied do not suggest that differences in these vitamins are playing a deciding role in hyperoxic protection in the high PUFA offspring, as menhaden oil diet was found to contain essentially the same amount of vitamin $\mathrm{E}$ as regular diet, and only $2 / 3$ the quantity of vitamin $\mathrm{A}$. (Lung tissue analysis of these vitamins in experimental and regular diet offspring is currently in progress.)

In addition, one of our major reasons for choosing the fish oil diet was to explore the role prostaglandins and thromboxanes (derived from arachidonic acid) might play in protecting the neonatal lung from hyperoxic damage. Studies by Hageman $e t$ al. (38), Smith et al. (39) and others found that specific eicosanoid levels were elevated in bronchoalveolar lavage fluid in association with prolonged hyperoxic challenge in rabbits, and that in adult rats, lipoxygenase blockade resulted in decreased mortality and indices of tissue damage during hyperoxic exposure (40). In addition, lipoxygenase products were increased in lavage fluid of infants with bronchopulmonary dysplasia, suggesting a possible etiologic role for these agents in clinical $\mathrm{O}_{2}$ toxicity (41). In the present study, we found that despite similar hyperoxic tolerance, the menhaden diet offspring had depressed lung levels of three major prostanoids compared to the regular diet offspring, whereas the high $n-6$ diet offspring demonstrated the highest mean values for the three prostanoids. These disparate prostaglandin and thromboxane levels, especially the large differences noted with $\mathrm{O}_{2}$ exposure (Fig. $2 \mathrm{~B}$ ), associated with similar hyperoxic tolerance between the high n-3 and high n-6 offspring, suggest that elevated lung PUFA is not functioning to protect against $\mathrm{O}_{2}$ toxicity through a prostaglandin-mediated mechanism.

There is thus reason to believe that increased lung tissue PUFA content itself may be responsible for protection against $\mathrm{O}_{2}$ toxicity, possibly through the free radical scavenging mechanism proposed by Dormandy (3). Various lines of evidence from the present and previous study support Dormandy's "alternate hypothesis" of a protective effect of high PUFA. First, two qualitatively different PUFA diets (high n-3 PUFA or high n-6 PUFA), but with a similar quantitative degree of polyunsaturation (i.e. double bond index of 173 for menhaden oil and 162 for safflower oil), confer essentially similar degrees of protection against hyperoxia. Secondly, both high PUFA diets result in increased unsaturation of the lung lipids; and this increased degree of unsaturation (or double bond index) is more pronounced in the triacylglycerol (nonmembrane) lipid fraction than in the phospholipid (membrane) fraction. And thirdly, the high PUFA diets do not appear to be exerting their protective effect through an antioxidant enzyme or prostanoid mechanism.

The results of this and our previous study deal with newborn rat offspring that manifest a relatively milder pulmonary pathologic response to hyperoxia compared to the human newborn infant. Nonetheless, these studies raise intriguing questions as to whether providing specific PUFA nutrition (perhaps a combination of n-6 and n-3 family fatty acids) to oxygen-requiring very low birth wt premature infants very soon after birth might be advantageous, not only to their nutritional status, but also to their ability to resist the toxic effects of oxygen and ventilator therapy.

Acknowledgments. The authors thank Mr. Miguel Martinez, Ms. Frances Martinez, and Mr. Laurie Nicol for their expert technical assistance, Ms. Terry Adirim for help with the pilot study, Mr. Jeremy Sosenko for his contribution to the poster presentation, and Mrs. Ondina Garcia-Pons for preparation of the manuscript.

\section{REFERENCES}

1. Frank L, Sosenko IRS 1987 Development of the lung antioxidant enzyme system in late gestation: implications for the prematurely born infant. J Pediatr 110:9-14

2. Sosenko IRS, Innis SM, Frank L 1988 Polyunsaturated fatty acids and protection of newborn rats from oxygen toxicity. J Pediatr 112:630-637

3. Dormandy TL 1969 Biological rancidification. Lancet 2:684-688

4. Dyerberg J, Bang HO 1978 A hypothesis on the development of acute myocardial infarction in Greenlanders. Scand $\boldsymbol{J}$ Clin Lab Invest 42:7-13

5. Dyerberg J, Bang HO, Stoffersen E, Moncada S, Vane JR 1978 Eicosapentaenoic acid and prevention of thrombosis and atherosclerosis. Lancet 2:117119

6. Needleman P, Raz A, Minkes NS, Ferendell JA, Sprecher H 1979 Triene prostaglandin: prostacyclin and thromboxane biosynthesis and unique biological properties. Proc Natl Acad Sci USA 76:944-948

7. Corey EJ, Shih C, Cashman JR 1983 Docosahexaenoic acid is a strong inhibitor of prostaglandin but not leukotriene biosynthesis. Proc Natl Acad Sci USA $80: 3581-3584$

8. Culp BR, Titus BG, Lands WEM 1979 Inhibition of prostaglandin biosynthesis by eicosapentaenoic acid. Prostaglandins Med 3:269-278

9. O'Brien JS, Fillerup DL, Mean JF 1964 Quantification of fatty acid and fatty aldehyde composition of ethanolamine, choline and serine glycerophosphatides in human cerebral grey and white matter. J Lipid Res 5:329-330

10. Anderson RE 1970 Lipids of ocular tissues IV: a comparison of the phospholipids from the retina of six mammalian species. Exp Eye Res 10:339-344

11. Clandinin MT, Chappell JE, Leong S, Heim T, Swyer PR, Chance GW 1980 Intrauterine fatty acid accretion rates in human brain: implications for fatty acid requirements. Early Hum Dev 4:121-129

12. McCord JM, Fridovich I 1960 Superoxide dismutase: an enzymatic function for erythrocuprein (hemocuprein). J Biol Chem 244:6049-6055

13. Holmes RS, Masters CJ 1970 Epigenetic interconversion of the multiple forms of mouse liver catalase. FEBS Lett 11:45-48

14. Paglia DE, Valentine WN 1967 Studies in the quantitative and qualitative characterization of erythrocyte glutathione peroxidase. J Lab Clin Med 70:158-159

15. Richards GM 1974 Modirications of the diphenylamine reactions giving in- 
creased sensitivity and simplicity in the estimation of DNA. Anal Biochem 57:369-376

16. Schacterle GR, Pollack RL 1973 A simplifed method for the quantitative assay of small amounts of protein in biological material. Anal Biochem 51:654655

17. Bligh EF. Dyer WJ 1959 A rapid method of total lipid extraction and purification. Can J Biochem Physiol 37:911-917

18. Mason RJ, Nellenbogen J, Clements JA 1976 Isolation of disaturated phosphatidylcholine with osmium tetroxide. J Lipid Res 17:281-284

19. Morrison WR $1964 \mathrm{~A}$ fast, simple and reliable method for the microdetermination of phosphorous in biological materials. Anal Biochem 11:218-224

20. Folch J, Lees M, Sloane-Stanley GH 1957 A simple method for the isolation and purification of total lipids from animal tissues. $J$ Biol Chem. 226:497509

21. Innis SM 1986 The activity of 3-hydroxy-3-methylglutaryl-CoA reductase and acyl CoA:cholesterol transferase in hepatic microsomes from male, female and pregnant rats: the effect of cholestyramine treatment and the relationship of enzyme activity to microsomal lipid composition. Biochim Biophys Acta 875:355-361

22. Innis SM, Clandinin MT 1981 Dynamic modulation of mitochondrial innermembrane lipids in rat heart by dietary fat. Biochem J 193:155-167

23. Lowry OH, Rosebrough NJ, Farr AL, Randall RJ 1951 Protein measurement with folin reagent. J Biol Chem 193.265-275

24. Bitman J, Wood DL, Hamosh M, Mehta NR 1983 Comparison of the lipid composition of breast milk from mothers of term and preterm infants. Am J Clin Nutr 83:300-312

25. Frank L, Lewis PL, Garcia-Pons T 1985 Intrauterine growth-retarded rat pups show increased susceptibility to pulmonary $\mathrm{O}_{2}$ toxicity. Pediatr Res 19:281 286

26. Fisher RA 1970 Statistical methods for research workers. Hafner Press, New York, 213-224

27. Lokesh BR, Bruckner G, Kinsella JE 1984 Reduction in thromboxane formation by $\mathrm{n}-3$ fatty acids enriched lung microsomes from rat and guinea pig following ingestion of dietary menhaden oil. Prostaglandins Leukotri Med $15: 337-348$

28. Swanson JE, Black JM, Kinsella JE 1987 Dietary n-3 polyunsaturated fatty acids: rate and extent of modification of fatty acyl composition of lipid classes of mouse lung and kidney. J Nutr 117:824-832
29. Nassar BA, Huang YS, Manku MS, Das UN, Morse N, Horrobin DF 1986 The influence of dietary manipulation with $n-3$ and $n-6$ fatty acids on liver and plasma phospholipid fatty acids in rats. Lipids 21:652-656

30. Huang YS, Nassar BA, Horrobin DF 1986 Changes of plasma lipids and long chain $n-3$ and n- 6 fatty acids in plasma, liver, heart and kidney phospholipids of rats fed variable levels of fish oil with or without cholesterol supplementation. Biochim Biophys Acta 879:22-27

31. Iritani N, Fujikawa S 1982 Competitive incorporation of dietary $w-3$ and $w-6$ polyunsaturated fatty acids into the tissue phospholipids in rats. J Nutr Sci Vitaminol (Tokyo) 28:621-629

32. Lokesh BR, Hsieh HL, Kinsella JE 1986 Alterations in the lipids and prostaglandins in mouse spleen following the ingestion of menhaden oil. Ann Nutr Metab 30:357-364

33. Magrum LJ, Johnston PV 1985 Effect of culture in vitro with eicosatetraenoic and eicosapentaenoic acids on fatty acid composition, prostaglandin synthesis and chemiluminescence of rat peritoneal macrophages. Biochim Biophys Acta 836:354-360

34. Neuringer M Connor WE, Petten CV, Barstad L 1984 Dietary omega-3 fatty acid deficiency and visual loss in infant rhesus monkeys. $\mathrm{J}$ Clin Invest $73: 272-276$

35. Lamptey MS, Walker BL 1976 A possible role for dietary linolenic acid in the development of the young rat. J Nutr 106:86-93

36. Storch J, Schacter D 1984 Dietary induction of acyl chain desaturases alters the lipid composition and fluidity of rat hepatocyte plasma membranes. Biochemistry 23:1165-1170

37. Houslay MD 1985 Regulation of adenylate cyclase activity by its lipid environment. Proc Nutr Soc 44:157-165

38. Hageman JR, Babler S, Lee SC, Cobb M, Pachman LM, Smith LJ, Hunt CE 1986 The early involvement of pulmonary prostaglandins in hyperoxic lung injury. Prostaglandins Leukotri Med 25:105-122

39. Smith LJ, Sommers E, Hunt CE, Pachman L 1986 Hyperoxic lung injury in mice: a possible protective role for prostacyclin. J Lab Clin Med 108:479488

40. Taniguchi I, Taki F, Takabi K 1986 Role of leukotriene $B_{4}$ in the genesis of oxygen toxicity in the lung. Am Rev Resp Dis 133:778-785

41. Stenmark KR, Eyzaguirre M, Westcott JY, Henson PM, Murphy RC 1987 Potential role of eicosanoids and PAF in the pathophysiology of bronchopulmonary dysplasia. Am Rev Respir Dis 136:770-772 